\title{
Evaluation of prescribing quality in nursing homes based on drug-specific indicators: The Bergen district nursing home (BEDNURS) study
}

\author{
Sabine Ruths \\ Research Unit for General Practice in Bergen, Unifob Health, Bergen, and \\ Section for General Practice, Department of Public Health and Primary Health Care, University of Bergen \\ Correspondence: Sabine Ruths, Research Unit for General Practice in Bergen, Unifob Health, Bergen, Kalfarveien 31, N-5018 Bergen, Norway \\ E-mail: sabine.ruths@isf.uib.no Telephone: +4755586129 Telefax: +4755586130
}

\begin{abstract}
Objectives: To examine prescribing quality among nursing home patients.

Methods: A cross sectional study in 23 nursing homes, based on drug charts. The evaluation of prescribing quality was based on selected drug-specific indicators established by the Swedish National Board of Health and Welfare. Logistic regression analysis was used to examine associations between prescribing indicators and predictors related to patient (age, gender, drug number) and institution (nurse and physician staff time) characteristics.

Results: A total of 1513 nursing home patients (76\% women, mean age 85 years) were included in the study. On average, the patients used 5.1 (SD 2.5) standing medications. Laxatives were most commonly used (58\%), followed by loop-diuretics (35\%), antidepressants (31\%), and anti-thrombotic agents (27\%). Altogether 850 $(56 \%)$ patients used at least one potentially inappropriate prescription (PIP), including long-term use of contact laxatives without proper indication (25\%), long-acting benzodiazepines (17\%), and anticholinergic drugs (16\%). The number of drugs used was the most important determinant for any PIP as well as for all individual indicators $(p<0.001)$. Relatively younger patients were more likely to receive any PIP, and in particular anticholinergic drugs, multiple psychotropic drugs, and interacting drugs $(\mathrm{p}<0.05)$.

Conclusion: Prescribing quality assessment by use of drug-specific indicators revealed great potentials for improving drug therapy in Norwegian nursing homes.
\end{abstract}

\section{INTRODUCTION}

Somatic nursing homes constitute with regard to number of patients the largest institutional level in Norway with a total capacity of about 38000 beds (1). The institutions are run by the municipalities on a non-profit basis. Patients with dementia represent $70-80 \%$ of the nursing home population (2). Adequate physician and nursing staff in terms of quantity (available staff time) and quality (knowledge, skills and attitudes) is required to provide high quality care. However, dimensioning of medical services in Norwegian nursing homes is generally considered sub-optimal.

Drug treatment is the most common medical intervention in nursing home patients. However, drug therapy decisions for these very old and frail patients remain a great challenge, due to 1) age-related pharmacokinetic and pharmacodynamic changes leading to increased drug sensitivity, 2) multi-morbidity indicating complex drug regimens, 3) dementia states raising diagnostic uncertainty and ethical dilemmas, and 4) a lack of evidence-based prescribing guidelines. Inappropriate drug use is an important and preventable safety concern in the care of elderly patients and has been associated with adverse drug reactions, hospitalization, and mortality (3). Various measures have been developed to evaluate prescribing quality, e.g. explicit indicators $(4,5)$, adverse drug events (6), and multidimensional indicators $(7,8)$. However, there is no universal definition of medication appropriateness, because quality may be assessed in different ways, depending on data available (prescription database vs. individual assessments), setting, and comprehensiveness.

The Swedish National Board of Health and Welfare has recently established explicit indicators for evaluation of drug therapy among elderly patients (9). The aims of this study were to examine prescribing quality in Norwegian nursing homes using selected drugspecific indicators on previously collected data, and to evaluate quality predictors with regard to patient and institutional factors.

\section{METHODS}

\section{Study population and data collection}

Patient recruitment and data collection has been described in detail elsewhere (8). Briefly, 23 nursing homes in greater Bergen agreed to participate in a cross sectional study auditing drug prescribing quality. All patients aged 65 years or more were eligible. Data was recorded by nursing home staff between November 1996 and January 1998. For each patient a onepage questionnaire was completed with regard to pati- 
ents' age and gender, all currently used medications, i.e. standing medications and drugs used "as required" the day before data collection (brand name, daily dose and treatment duration), indication(s) for each drug and principal diagnoses. Drugs were classified according to the Anatomical Therapeutical Chemical (ATC) classification system (10). Based on this information, a comprehensive medication review has been conducted previously (8). The present cross-sectional study is a re-analysis of these data.

\section{Prescribing quality indicators}

Although most studies of prescribing quality in elderly patients are based on explicit criteria established in the U.S. by Beers et al. $(4,5)$, these criteria are considered less useful in the Norwegian setting because half of the medications on these lists are not approved here. Norwegian indicators for the evaluation of drug therapy for elderly are under preparation (11), but they were not yet available for the purpose of this study. The Swedish National Board of Health and Welfare has introduced prescribing quality indicators for evaluation of drug therapy among elderly patients, including drug-specific and diagnosis-specific indicators (9). Most of these indicators are derived from previously published explicit criteria by e.g. Beers $(4,5)$, McLeod (12), and van Dijk (13), but adapted to the Swedish drug formulary. The 25 drug-specific indicators comprise drugs to be avoided, drugs to be used on special indications only, drug regimens, drug dosage, polypharmacy, and interactions. The diagnosis-specific indicators include drug therapy for 11 common diagnoses among the elderly. In this study, evaluation of prescribing quality was based on nine drug-specific indicators, Box 1. Drugs on special indications only, and diagnosis-specific indicators were not included, because the quality of available diagnostic information could not be examined. Drug-drug interactions were assessed using the Norwegian DRUID database (14) instead of the Swedish FASS database, to secure compatibility with the Norwegian drug formulary and for practical reasons (online access).

\section{Statistical analyses}

Student's t-test was performed to compare means (continuous variables), and $\chi^{2}$ test to explore differences between proportions (categorical data). Associations were examined using Pearson's correlation test. Single-step multivariate logistic regression analysis was used to examine the association between prescribing quality indicators (dependant variable: any indicator, individual indicators) and possible predictors (independent variables: patients' age and gender, number of medications used per patient, nursing and physician staff time). Data analysis was performed using SPSS 13.0 for Windows. $\mathrm{P}$ values $\leq 0.05$ were considered statistically significant.
Box 1. Drug-specific indicators established by the Swedish National Board of Health and Welfare (9) that were used in this study. Low proportions of each indicator should indicate good prescribing quality.

- Proportion of patients taking long-acting benzodiazepines: Diazepam, nitrazepam, flunitrazepam

- Proportion of patients taking anticholinergic drugs: High dose antipsychotics, cyclic antidepressants, antihistamines, hydoxyzin, anti-Parkinson drugs, spasmolytics, antiarrhythmic drugs class Ia, anti-emetics

- Proportion of patients taking hypnotics daily for more than 1 month: Nitrazepam, flunitrazepam, midazolam, zopiclone, zolpidem, chlometiazol

- Proportion of patients taking NSAIDs daily for more than 3 months: Indometacin, sulindac, diclofenac, ketorolac, piroxicam, meloxicam, ibuprophen, naproxen, ketoprophen, dexibuprophen

- Proportion of patients taking contact laxatives for more than 3 weeks without indication, e.g. concomitant use of strong opioid analgesics: Bisacodyl, sennaglycosides

- Proportion of patients taking 3 or more psychotropic drugs: Antipsychotics, anxiolytics, hypnotics, antidepressants

- Proportion of patients taking 2 or more antipsychotic drugs: "Typical" (first generation), "atypical" (second generation) drugs

- Proportion of patients taking 2 or more benzodiazepines: Anxiolytics, hypnotics

- Proportion of patients with potential drug-drug interactions according to the Norwegian DRUID database (14): A. Drug combinations that should be avoided; B. Drug combinations that should be given with at least 2-3 hours interval; C. Drug combinations that can lead to effect alterations but can be managed with dose adjustment or monitoring; D. Drug combinations that may change drug effect but are regarded to be of little clinical importance ("academic interest")

\section{Ethics and confidentiality}

Data was collected originally as part of a quality assurance project that was approved by the nursing home director and physician(s) of the participating institutions. However, approval from the Regional Committee for Medical Research Ethics or the Norwegian Directorate has not been sought. Data records (questionnaires) were marked with an individual patient code by nursing home staff. The lists linking patients' name to the codes were kept by the nursing home administrators, though individual patients could not be identified by the researchers.

\section{RESUlts}

Altogether 1513 nursing home patients were included in the study, with a mean age of 85 years. Women accounted for $76 \%$ of all patients and were generally older than the men $(85.7$ vs. $82.8, \mathrm{p}<0.001)$. On average, the patients had 3.0 (SD 1.5) active medical conditions and used 5.1 (SD 2.5) standing medications. Only 18 patients (1.2\%) did not use any drug. Medication numbers did not vary with patients' gender 
$(p=0.82)$, but declined with increasing age $(p=0.03)$. Laxatives were the most commonly used drugs (58\%), followed by loop-diuretics (35\%), antidepressants (31\%), and anti-thrombotic agents (27\%), Table 1 .

Based on the nine selected drug-specific indicators, $850(56 \%)$ patients used at least one potentially inappropriate prescription (PIP). The medications most frequently questioned include long-term therapy with contact laxatives without concomitant use of opioids (25\%), long-acting benzodiazepines (17\%), and anticholinergic drugs (16\%), Table 2 .

Logistic regression analysis of predictors with regard to patients and institutions revealed that the number of medications used was the most important determinant for any PIP as well as for all individual indicators $(p<0.001)$, Table 3 . Relatively younger patients were slightly more likely to receive any PIP, and in particular anticholinergic drugs, multiple psychotropic drugs, and interacting drugs $(p<0.05)$. Relatively more available nursing staff time was associated with more use of benzodiazepines and laxatives, but less use of anticholinergic drugs $(p<0.05)$. Relatively more physician staff time was associated with less PIP, but more use of NSAIDs $(\mathrm{p}<0.05)$.

\section{DisCUSSION}

Based on selected drug-specific indicators, potentially inappropriate prescribing was found in $56 \%$ of the nursing home patients. Lower prescribing quality was associated with the use of relatively more drugs and relatively younger patient age.

\section{Methodological considerations}

The almost complete data sets for all participants contributed to a high internal validity of the study. However, data collection was conducted ten years ago, and drug utilization patterns may have changed in the meantime. Patient demographics and institutional characteristics of the participating nursing homes averaged the national figures, which strengthens the external validity. But the lack of national statistics on patient morbidity and drug prescribing in nursing homes impairs the ability to examine the generalizability of the results. Although indications for each drug as well as principal diagnoses were obtained for the participating patients, the quality and completeness of these data could not be examined due to a lack of documentation for the diagnostic information. Therefore, diagnostic information was disregarded in this study, and quality assessment was limited to drugspecific indicators.

\section{Prescribing quality}

The average number of standing medications found in this study fits with the lower range of figures reported from European, Australian and U.S. institutions (13, 15,16). The spectrum of most frequently prescribed
Table 1. The $10 \mathrm{ATC}^{1}$ drug groups most frequently used by nursing home patients $(\mathrm{n}=1513)$.

\begin{tabular}{llcc}
\hline & & \multicolumn{2}{c}{ Prevalence } \\
\cline { 3 - 4 } ATC ${ }^{1}$ group & Drug & $\mathrm{N}$ & $\%$ \\
\hline A06A & Laxatives & 870 & 57.5 \\
C03C & Loop-diuretics & 532 & 35.2 \\
N06A & Antidepressants & 466 & 30.8 \\
B01A & Anti-thrombotic agents & 409 & $27.0^{2}$ \\
N05A & Antipsychotics & 339 & 22.4 \\
G03C & Estrogens & 270 & $23.8^{3}$ \\
N02B & Non-opioid analgesics & 250 & 16.5 \\
N05B & Anxiolytics & 245 & 16.2 \\
N05C & Hypnotics & 234 & 15.5 \\
N02A & Opioiod analgesics & 195 & 12.9 \\
\hline
\end{tabular}

${ }^{1}$ Anatomical Therapeutical Chemical classification system (10)

${ }^{2}$ Low dose Acetylsalicylic acid: $23.5 \%$

${ }^{3}$ Women

Table 2. Prevalence of potentially inappropriate prescribing (PIP) for nursing home patients $(\mathrm{n}=1513)$.

\begin{tabular}{lrr}
\hline Indicator & $\mathrm{n}$ & \multicolumn{1}{c}{$\%$} \\
\hline Long-acting benzodiazepines & 257 & 17.0 \\
Anticholinergic drugs & 248 & 16.4 \\
Hypnotics daily $>$ 1 month & 202 & 13.4 \\
NSAID $^{1}$ daily $>3$ months & 63 & 4.2 \\
Contact laxatives $>3$ weeks, no indication & 375 & 24.8 \\
Three or more psychotropic drugs & 90 & 5.9 \\
Two or more antipsychotic drugs & 26 & 1.7 \\
Two or more benzodiazepines & 29 & 1.9 \\
Drug-drug interaction ${ }^{2}$ & 178 & 11.8 \\
Any quality indicator & 850 & 56.2 \\
\hline${ }^{1}$ Non steroidal anti-inflammatory drug & \\
${ }^{2}$ The Norwegian DRUID database (14) includes 4 categories: A. \\
Drug combinations that should be avoided (n=13); B. Drug combi- \\
nations that should be given with at least 2-3 hours interval (n=4); \\
C. Drug combinations that can lead to effect alterations but can be \\
managed with dose adjustment or monitoring (n=94); D. Drug \\
combinations that may change drug effect but are regarded to be of \\
little clinical importance (“academic interest") (n=67).
\end{tabular}

drugs, including laxatives, psychotropics, cardiovascular drugs and analgesics, is in line with international studies $(13,15,17)$.

Comparisons with other studies are hampered by methodological differences, e.g. the use of explicit indicators on computerized pharmacy databases in large scaled studies $(18,19)$ vs. comprehensive medication reviews including clinical information on individual patients in smaller scaled studies $(7,8)$. Explicit prescribing indicators, in particular those established by Beers et al. $(4,5)$, are widely used, revealing between 25 and $49 \%$ prevalence of PIPs in U.S. and European nursing homes $(18,19)$. Partly based on identical drug-specific Swedish indicators, the 56\% prevalence of PIP demonstrated in the present study was slightly lower than the $70 \%$ prevalence in a recent Swedish nursing home study (17) that was based on five drug-specific indicators (9). The four indicators 
Table 3. Single-step multivariate logistic regression analysis of potentially inappropriate prescribing among $1396^{1}$ nursing home patients by patients' age, gender, numbers of drugs used, and available nursing and physician staff time (number of full-time positions/100 patients).

\begin{tabular}{|c|c|c|c|c|c|c|c|c|c|c|c|c|c|c|c|c|c|c|c|c|}
\hline \multirow{2}{*}{$\begin{array}{l}\text { Independent } \\
\text { variable }\end{array}$} & \multicolumn{2}{|c|}{$\begin{array}{l}\text { Any quality } \\
\text { indicator }\end{array}$} & \multicolumn{2}{|c|}{$\begin{array}{c}\text { Long-acting } \\
\text { benzo- } \\
\text { diazepines }\end{array}$} & \multicolumn{2}{|c|}{$\begin{array}{c}\text { Anticholi- } \\
\text { nergic drugs }\end{array}$} & \multicolumn{2}{|c|}{$\begin{array}{c}\text { Hypnotics } \\
\text { daily }>1 \\
\text { month }\end{array}$} & \multicolumn{2}{|c|}{$\begin{array}{c}\text { NSAID daily } \\
>3 \text { months }\end{array}$} & \multicolumn{2}{|c|}{\begin{tabular}{|c} 
Contact \\
laxatives \\
$>3$ weeks, no \\
indication
\end{tabular}} & \multicolumn{2}{|c|}{$\begin{array}{l}\text { Three or more } \\
\text { psychotropics }\end{array}$} & \multicolumn{2}{|c|}{$\begin{array}{c}\text { Two or more } \\
\text { antipsychotics }\end{array}$} & \multicolumn{2}{|c|}{$\begin{array}{c}\text { Two or more } \\
\text { benzo- } \\
\text { diazepines }\end{array}$} & \multicolumn{2}{|c|}{$\begin{array}{l}\text { Drug-drug } \\
\text { interaction }\end{array}$} \\
\hline & AOR & $95 \% \mathrm{CI}$ & AOR & $95 \% \mathrm{CI}$ & AOR & $95 \% \mathrm{CI}$ & AOR & $95 \% \mathrm{CI}$ & AOR & $95 \% \mathrm{CI}$ & AOR & $95 \% \mathrm{CI}$ & AOR & $95 \% \mathrm{CI}$ & AOR & $95 \% \mathrm{CI}$ & AOR & $95 \% \mathrm{CI}$ & AOR & $95 \% \mathrm{CI}$ \\
\hline Patien & 0.98 & $\begin{array}{l}0.97- \\
1.00^{*}\end{array}$ & 1.01 & $\begin{array}{l}0.99- \\
1.03\end{array}$ & 0.97 & $\begin{array}{l}0.95- \\
0.99 *\end{array}$ & 1.01 & $\begin{array}{l}0.98- \\
1.03 \\
\end{array}$ & 1.04 & $\begin{array}{l}0.99- \\
1.08\end{array}$ & 1.01 & $\begin{array}{l}0.99- \\
1.03 \\
\end{array}$ & 0.95 & $\begin{array}{l}0.92- \\
0.99 *\end{array}$ & 0.94 & $\begin{array}{l}0.89- \\
0.99 *\end{array}$ & 0.97 & $\begin{array}{l}0.91- \\
1.03 \\
\end{array}$ & 0.97 & $\begin{array}{l}0.95- \\
0.99 *\end{array}$ \\
\hline $\begin{array}{l}\text { Female } \\
\text { patient }\end{array}$ & 0.91 & $\begin{array}{c}0.70- \\
1.19 \\
\end{array}$ & 0.96 & $\begin{array}{l}0.68- \\
1.36\end{array}$ & 1.13 & $\begin{array}{c}0.80- \\
1.60\end{array}$ & 0.93 & $\begin{array}{c}0.64- \\
1.34 \\
\end{array}$ & 1.09 & $\begin{array}{l}0.56- \\
2.13 \\
\end{array}$ & 0.98 & $\begin{array}{c}0.73- \\
1.31 \\
\end{array}$ & 1.02 & $\begin{array}{c}0.60- \\
1.73 \\
\end{array}$ & 0.70 & $\begin{array}{l}0.30- \\
1.66\end{array}$ & 1.95 & $\begin{array}{l}0.65- \\
5.90\end{array}$ & 0.81 & $\begin{array}{c}0.55- \\
1.19 \\
\end{array}$ \\
\hline $\begin{array}{l}\text { Number of } \\
\text { drugs }\end{array}$ & 1.38 & $\begin{array}{c}1.31- \\
1.45^{* *}\end{array}$ & 1.30 & \begin{tabular}{|c|}
$1.22-$ \\
$1.37 * *$ \\
\end{tabular} & 1.21 & \begin{tabular}{|c|}
$1.14-$ \\
$1.28 * *$
\end{tabular} & 1.29 & $\begin{array}{c}1.21- \\
1.37 * *\end{array}$ & 1.31 & $\begin{array}{c}1.19- \\
1.44 * *\end{array}$ & 1.13 & $\begin{array}{c}1.08- \\
1.18^{* *}\end{array}$ & 1.44 & \begin{tabular}{|c|}
$1.33-$ \\
$1.57 * *$ \\
\end{tabular} & 1.27 & \begin{tabular}{|c|}
$1.12-$ \\
$1.44 * *$ \\
\end{tabular} & 1.34 & \begin{tabular}{|c|}
$1.18-$ \\
$1.52^{* *}$
\end{tabular} & 1.28 & $\begin{array}{c}1.20- \\
1.36^{* *}\end{array}$ \\
\hline $\begin{array}{l}\text { Nursing staff } \\
\text { time }\end{array}$ & 1.04 & $\begin{array}{l}1.00- \\
1.08^{*}\end{array}$ & 1.05 & $\begin{array}{l}1.00- \\
1.10^{*}\end{array}$ & 0.96 & $\begin{array}{l}0.91- \\
0.99 *\end{array}$ & 0.99 & $\begin{array}{l}0.95- \\
1.05\end{array}$ & 0.94 & $\begin{array}{l}0.86- \\
1.02 \\
\end{array}$ & 1.06 & $\begin{array}{l}1.02- \\
1.11 *\end{array}$ & 0.99 & $\begin{array}{l}0.92- \\
1.07\end{array}$ & 1.03 & $\begin{array}{l}0.91- \\
1.17 \\
\end{array}$ & 1.15 & $\begin{array}{c}0.99- \\
1.32 \\
\end{array}$ & 1.01 & $\begin{array}{l}0.96- \\
1.07\end{array}$ \\
\hline $\begin{array}{l}\text { Physician } \\
\text { staff time }\end{array}$ & 0.14 & $\begin{array}{l}0.02- \\
0.78^{*}\end{array}$ & 0.20 & $\begin{array}{l}0.02- \\
1.73 \\
\end{array}$ & 1.37 & $\begin{array}{l}0.16- \\
11.79 \\
\end{array}$ & 1.55 & $\begin{array}{l}0.15- \\
16.49 \\
\end{array}$ & $\begin{array}{c}87.7 \\
8 \\
\end{array}$ & $\begin{array}{l}1.28- \\
6036^{*}\end{array}$ & 0.19 & $\begin{array}{l}0.03- \\
1.28\end{array}$ & 2.83 & $\begin{array}{l}0.10- \\
81.92 \\
\end{array}$ & $\begin{array}{c}0.00 \\
6\end{array}$ & 0-2.19 & 0 & $0-0.16$ & 0.48 & $\begin{array}{l}0.04- \\
5.95\end{array}$ \\
\hline $\begin{array}{l}\text { Goodness-of- } \\
\text { fit } \chi^{2}(\mathrm{P})\end{array}$ & \multicolumn{2}{|c|}{$12.88(.12)$} & \multicolumn{2}{|c|}{$10.69(.22)$} & \multicolumn{2}{|c|}{$14.47(.07)$} & \multicolumn{2}{|c|}{$17.19(.03)$} & \multicolumn{2}{|c|}{$10.89(.21)$} & \multicolumn{2}{|c|}{$11.59(.17)$} & \multicolumn{2}{|c|}{$13.77(.09)$} & \multicolumn{2}{|c|}{$5.51(.70)$} & \multicolumn{2}{|c|}{$7.04(.53)$} & \multicolumn{2}{|c|}{$19.88(.01)$} \\
\hline
\end{tabular}

${ }^{1} 1396$ patients were included in the analyses due to incomplete data for 117 patients

$\mathrm{AOR}=$ adjusted odds ratio; $\mathrm{CI}=$ confidence interval; * significant at the .05 level; ** significant at the .001 level

included in both studies revealed a similar prevalence of long-acting benzodiazepines and anticholinergic drugs, whereas polypsychopharmacology (Norway 6\% vs. Sweden 39\%) and drug-drug interactions (Norway, including categories A-D: $12 \%$ vs. Sweden, including only categories $\mathrm{C}$ and D: $12 \%$ and $45 \%$, respectively) were far more prevalent in the Swedish study. The discrepancies in drug-drug interactions are surprising because both databases rely on documented pharmacokinetic and pharmacodynamic interaction mechanisms. They may possibly be due to differences with regard to structure and content of these databases (not examined in this study), as well as differences between study populations. While the present study was based on unselected nursing home populations, the Swedish study was restricted to multi-dose users, i.e. patients on multiple medications that are machine dispensed.

Extensive use of long-acting benzodiazepines and/ or anticholinergic drugs in nursing homes has been reported in other studies and is considered problematic due to an increased risk of cognitive and physical impairment $(13,15,20)$. Contact laxatives given as standing medication without proper indication was the most prevalent PIP found in this study. However, the prevalence varied much between nursing homes (data not shown), and may indicate great differences with regard to prescribing culture and habits.

Polypharmacy emerged as the strongest predictor of any PIP and all single indicators in this study. However, many chronic conditions indicate complex treatment regimens, leading to "rational polypharmacy" that may be justified by diagnostic indications. Drug utilization numbers should therefore be interpreted with caution (21). The inverse relationship of patients' age and some indicators found here was in line with the Swedish study by Bergman et al. (17). This association may possibly reflect a "survival of the fittest", i.e. patients institutionalized due to very old age but otherwise relatively healthy and using few medications.

There were large variations between the institutions with regard to prevalence of PIP and available staff time (data not shown). Statistically significant associations with available staff time were demonstrated for several indicators. However, the effect size was rather small with regard to nursing staff time (AOR between 0.96 and 1.05), and confidence intervals were rather large with regard to physician staff time (Table 3). Moreover, the cross-sectional study design does not allow for conclusions about causal relationships between any of the variables. However, one should expect that staff makes an important difference with regard to medical treatment including drug therapy. The question arises as whether quantity (available staff time) or quality (knowledge, skills and attitudes) is most important, or perhaps, a combination. Further studies are needed to elucidate this question.

\section{Impact}

Explicit indicators have the advantage of being independent from users' knowledge, and they are useful for screening of large databases. On the other hand, they are rigid tools not taking into consideration differences between individual patients. They are based on expert consensus rather than evidence from clinical studies. Drug formularies and treatment traditions vary between countries and indicate limitations to apply criteria in different geographic areas. To remain 
useful, explicit criteria need to be updated regularly. Explicit indicators may detect high risk prescribing, but do not allow for identification of other drug-related problems, e.g. undertreatment, or inappropriate use of medications that are in principle regarded appropriate for the elderly.

The rationale of identifying inappropriate prescribing is to prevent adverse health outcomes. Although PIP according to Beers' criteria is associated with an increased risk of hospitalization and mortality in the community setting, evidence is inconclusive with regard to nursing homes (3). Moreover, Laroche et al. have questioned a causal relationship, by demonstrating that only $6 \%$ of adverse drug events in hospitalized patients were directly attributable to PIP (22).

Although a national prescription database (NorPD) has been established in 2004, drug prescribing data for patients institutionalized in nursing homes or hospitals is not included. As a consequence, prescribing information for these patients has still to be collected manually. This may probably explain the scarcity of drug utilization studies in Norwegian nursing homes. However, complex drug therapy and an increased risk of adverse outcomes in these very old frail patients indicate an urgent need for quality assessment and improvement. Future research should include national prescribing quality indicators, and examine the predictive value of these indicators with regard to clinical endpoints.

\section{CONCLUSIONS}

Prescribing quality assessment by drug-specific indicators revealed great potentials for improving drug therapy in Norwegian nursing homes. Strategies should be implemented to detect and improve inappropriate prescribing. The possible function of explicit indicators in a continuing process of quality assessment and improvement deserves further investigations.

\section{ACKNOWLEDGEMENTS}

I want to express my gratitude to the participating nursing homes in Bergen. The committed contribution to the BEDNURS study by professors Jørund Straand and Harald A. Nygaard is thankfully acknowledged.

\section{REFERENCES}

1. Statistics Norway. http://www.ssb.no (accessed 30.12.2007).

2. Engedal K, Haugen PK. The prevalence of dementia in a sample of elderly Norwegians. Int $J$ Geriatr Psychiatry 1993; 8: 565-570.

3. Jano E, Aparasu RR. Healthcare outcomes associated with Beers' criteria: a systematic review. Ann Pharmacother 2007; 41: 438-447.

4. Beers $\mathrm{MH}$. Explicit criteria for determining potentially inappropriate medication use by the elderly. An update. Arch Intern Med 1997; 157: 1531-1536.

5. Fick DM, Cooper JW, Wade WE, Waller JL, Maclean JR, Beers MH. Updating the Beers criteria for potentially inappropriate medication use in older adults: Results of a US consensus panel of experts. Arch Intern Med 2003; 163: 2716-2724.

6. Gurwitz JH, Field TS, Avorn J, McCormick D, Jain S, Eckler M, et al. Incidence and preventability of adverse drug events in nursing homes. Am J Med 2000; 109: 87-94.

7. Hanlon JT, Schmader KE, Samsa GP, Weinberger M, Uttech KM, Lewis IK, et al. A method for assessing drug therapy appropriateness. J Clin Epidemiol 1992; 45: 1045-1051.

8. Ruths S, Straand J, Nygaard HA. Multidisciplinary medication review in nursing home residents: what are the most significant drug-related problems? The Bergen district nursing home (BEDNURS) study. Qual Saf Health Care 2003; 12: 176-180.

9. Socialstyrelsen [Swedish National Board of Health and Welfare]. Indicators for evaluation of the quality of drug therapy among elderly. Report 2003-110-20. http://www.socialstyrelsen.se/NR/rdonlyres/A65367AB8F2A-4063-BC79-13103784A838/986/200311020.pdf (accessed 30.12.2007).

10. World Health Organisation. ATC Index with DDDs and Guidelines for ATC classification and DDD assignment, 2005. http://www.who.org (accessed 30.12.2007).

11. Straand J, Fetveit A, Rognstad S, Gjelstad S, Brekke M, Dalen I. Study protocol: A cluster-randomized educational intervention to reduce inappropriate prescription patterns for elderly patients in general practice The prescription peer academic detailing (Rx-PAD) study. BMJ Health Services Research 2006; 6: 72 http://www.biomedcentral.com/1472-6963/6/72 (11.01.08).

12. McLeod PJ. Defining inappropriate practices in prescribing for elderly people: a national consensus panel. CMAJ 1997; 156: 385-391.

13. van Dijk KN, Pont LG, de Vries CS, Franken M, Brouwers RJ, de Jong-van den Berg LT. Prescribing indicators for evaluating drug use in nursing homes. Ann Pharmacother 2003; 37: 1136-1141.

14. DRUID (Drug Information Database) http://www.interaksjoner.no/ (accessed 10.01.08). 
15. Roberts MS, King M, Stokes JA, Lynne TA, Bonner CJ, McCarthy S, et al. Medication prescribing and administration in nursing homes. Age Ageing 1998; 27: 385-392.

16. Avorn J, Gurwitz JH. Drug use in the nursing home. Ann Intern Med 1995; 123: 195-204.

17. Bergman $\AA$, Olsson J, Carlsten A, Waern M, Fastbom J. Evaluation of the quality of drug therapy among elderly patients in nursing homes. Scand J Prim Health Care 2007; 25: 9-14.

18. Gupta G, Rappaport HM, Bennett LT. Inappropriate drug prescribing and related outcomes for elderly Medicaid beneficiaries residing in nursing homes. Clin Ther 1996; 18: 183-196.

19. Dhalla IA, Anderson GM, Mamdani MM, Bronskill SE, Sykora K, Rochon PA. Inappropriate prescribing before and after nursing home admission. J Am Geriatr Soc 2002: 50: 995-1000.

20. Landi F, Russo A, Liperoti R, Cesari M, Barillaro C, Pahor M, Bernabei R, Onder G. Anticholinergic drugs and physical function among frail elderly population. Clin Pharmacol Ther 2007; 81: 235-241.

21. Viktil KK, Blix HS, Moger TA, Reikvam A. Polypharmacy as commonly defined is an indicator of limited value in the assessment of drug-related problems. Br J Clin Pharmacol 2006; 63: 187-195.

22. Laroche ML, Charmes JP, Nouaille Y, Picard N, Merle L. Is inappropriate medication use a major cause of adverse drug reactions in the elderly? Br J Clin Pharmacol 2007; 63: 177-186. 